\title{
Avogadro Limit Washed out by Nano-Associates of Water which Continue as Information Carriers in Serial Dilutions and End up with Generalized Concept of Medicines
}

Abstract

As per Avogadro number high potency (beyond 12c) homeo-medicines cannot have even traces of the starting material. So, how can they be medicines? If distinguishing chemical formula is the criterion, then they are non-medicines. Still, they continue to cure diseases for over two centuries. It implies a necessity to reorient our thinking. Thanks to the Structural Model backed by Quantum Electrodynamics (QED), we get the desired reorientation. QED predicts existence of ice-like structures called Coherent Domains (CD) in water at room temperature which is confirmed experimentally. These CDs are information carriers through serial dilution because their shape and size get influenced by factors like impurities, ions of other substances, large foreign molecules, physical perturbations, electromagnetic field etc. Unhindered by Avogadro limit the CDs continue their journey in homeopathic potentisation. These structures, in their turn, influence near-matching bio-molecules to serve as medicines, like antibiotics, leading to a generalized concept of medicine.

Keywords: Structural Model; Quantum Electrodynamics (QED); CDs as information carriers; serial dilution; Generalized concept of medicine

\section{Review Article}

Volume 9 Issue 4 - 2017

\section{Mahata $\mathrm{CR}^{1,2 *}$ \\ ${ }^{1}$ Hony, Emeritus Professor, CEM Kolaghat, India \\ ${ }^{2}$ Hony, Visiting Professor, IIEST Shibpur, India}

*Corresponding author: Chitta Ranjan Mahata, Hony Emesritus Scientist, IIEST, Flat-C2, 50/1 College Road, Howrah-711103, WB, Shibpur, India, Tel: 91-9433739180; Email: crmahata@gmail.com

Received: June 27, 2017 | Published: November 24, 2017

\section{Background}

Medicines or not, medicinal cure or placebo effect - this kind of controversy continues to accompany homeopathy almost since its inception. The dictate of Avogadro number is that chemically all potencies above $12 \mathrm{c}$ will be just the vehicle. So, they must be fake medicines and cannot cure any disease. Whatever cure is observed is just placebo effect or mental cure. Holding on to this view sharp criticism has been directed against homeopathy, sometimes demanding a ban on this system. Even eminent scientist like J Benveniste and Nobel Laureate L Montagnier were not spared for their implied support to homeopathy. That science is yet to give a satisfactory explanation of homeo-mystery is a fact. It is also a fact that science advances by accepting its limitations and striving to find answer to unresolved questions, be it related to homeopathy or something else. Let us adhere to this principle.

The real test of a medicine should be its capability of curing disease vis-à-vis altering the state of health. Homeo-medicines passed this test again and again for over two centuries. Further, once a person feels the subtle, safe and superior effect of homeomedicines in his body he becomes a permanent believer in homeopathy. No data can wipe out his faith in homeopathy. Statistics is no yardstick for him. This is why homeopathy is not only surviving but flourishing. Further, Placebo cure hypothesis advanced by homeo-skeptics has serious drawbacks: (a) Placebo effect or mental cure is not valid for benefits to babies, animals and plants where mind does not have any role. (b) Granting a place to mental cure or placebo effect, it should have been predominant for glamorous main stream medicines instead of poor homeopathy. (c) If mental cure is so easily achievable by common people then we should throw all medicines to dust bin. (d) Mind is not known to have any quantifiable active ingredient. So, mental cure is a self-contradictory hypothesis. It is confusion between cure by chemical-free homeo-medicines and cure by transcendental powers of yogis and saints, which may unknowingly manifest even in ordinary individuals in some rare moments. But, in normal life one has to depend on medicines and not on transcendental powers from outside or sudden rise of that power from within. So, let us concentrate on the business of homeo-mystery by appropriate reorientation of our thinking.

\section{Homeo-Mystery - Medicinal Information Carried by} Water Structures?

Homeo-mystery is closely linked with mystery of water. Innumerable tiny ice-crystals or icicles were observed in water at room temperature, writes B. Sergeev [1]. These icicles had countless forms and their shape and size were found to be influenced by factors like ions of other substances, impurities, large foreign molecules etc. [2]. Literature also reported health/ disease of cell constituents to be reflected in structure of cell water [3-5], ability of icicles to fit with matching bio-molecules or crushing and expelling mismatched large molecules from within ice structures or straighten up bio-molecules in case of no-greatmismatch [1]. Based on this information CR Mahata [6] advanced a logically consistent 'structural model' of medicines in a research 
paper in 1997. He argued that the ice-like structures had the possibility of being structurally-coded information carriers as they were susceptible to influence of factors stated above. Their Potential to take infinite structural variations in natural conditions (subjected to random influences) suggested that specificity could be a reality under controlled conditions. That is, the potentisation process of homeopathy is likely to generate coded molecular clusters specific to the original medicinal substance and its potency.

It may be added that a few years back ED Giudice \& G Preparata, et al. $[7,8]$ had shown from Quantum Electro-Dynamic (QED) coherent calculations that liquid water at room temperature is a mixture of coherent (coherence domain, CD) and incoherent water. The CDs are ice-like structures and quite stable. It was confirmed by a number of researchers [9-17].

V Elia, R Germano, E Napoli present a good review [18] of evidence of formation of dissipative structures in liquid water induced by three kinds of low energy physical perturbations: iteratively filtered water (IFW), iteratively nafionated water (INW) and extremely diluted solution (EDS). V Elia and his co-workers published a number of investigations on IFW [1924], on INW [25-28] and EDS [29-55]. On the basis of large number experiments using instruments like flux calorimetry, conductometry, pHmetry and galvanic cell electrode potential, FT-IR, Fluorescence microscopy, UV-VIS, light scattering, Atomic Force Microscope this group came to the conclusion that the alteration of properties subjected to these perturbations were not because of chemical impurities or measurement errors. They were information related to the substance under consideration and its history.

Side by side, we find another good review by AI Konovalov \& IS Ryzhkina [56] dealing mostly with Russian publications. It is focused on nano-associates. It gives us an idea of the extensive work done in this area in Russia. The group led by Academician A I Konovalov studied dilution phenomena of a number of chemicals [57-77]. They found generation of supra-molecular systems or associates. The substances were not homeopathic medicines. It shows that formation of nano-associates in diluted and vigorously shaken solutions is a common phenomenon. It was also observed that action of the external electromagnetic field is the condition of nano-associate formation in highly diluted aqueous solutions [7782]. It was the finding of Luc Montagnier as well [83]. In a series of three papers T A Yinnon reports domains formation mediated by electromagnetic fields in very diluted and succussed aqueous solutions [84-86]. She also reports about domain formation in dilute aqueous solutions $[87,88]$.

So, generation of nano-associates, also called as dissipative structures, with their changes in properties in diluted and succussed aqueous solutions seems to be satisfactorily established. Nano-associates are chemically just $\mathrm{H}_{2} \mathrm{O}$ but their properties change with change of perturbations. So, they may be considered as information carriers. Further, perturbations in EDS are same as homeopathic potentisation. Consequently, nanoassociates may be considered as carriers of information related to the starting material and the degree of potentisation. And nanoassociates (chemically just water) being information carriers they cannot be anything other than structural variations.
Taking a generalized view it may also be added that the CDs or nano-associates can be promising information carriers because, their shape and size were found to be influenced by things like impurities, ions of other substances, electro-magnetic field, low energy physical perturbations etc. In natural environment these factors are uncontrolled and random in nature. This leads to infinite variations of their structures. But, the potentisation process of homeopathy is a controlled one and can generate water structures specific to the starting material and potency. So, the CD's contained in various diluted plus succussed (potentised) substances will turn out to be carriers of information about medicines in the form of structured molecular groups, called as 'nano-associates' of water molecules as their sizes fall in the nanometer range. Nano-associates of $\mathrm{p}^{\text {th }}$ potency will act causative agents for the $(p+1)^{\text {th }}$ potency, where $p$ stands for an arbitrary potency. The chain can continue even without the starting chemical beyond 12c potency. Consequently, Avogadro number will lose its power to discard homeo-medicines of any potency. Here, chemistry is superseded by physical structure. As such, the potentisation process of homeopathy will never be hindered by the Avogadro limit. This is of great significance.

Further, the information contained will be related to medicine plus its potency, but it will not be exact memory. For, 'watermemory' tends to suggest conservation of material image of solute in water. It will not be proper to call these nano-sized objects as 'nano-particles' either, because they mean particles of same chemistry as the starting material.

Using the technique of Dielectric Dispersion CR Mahata and his co-workers obtained information about dimensions of water structures and have brought out the structural aspect of homeomedicines through a number of papers [89-93]. The information was in terms of resonance frequencies of the structures in electric field. It follows the well known equation for resonance in longitudinal mode of vibration,

\section{$2 \times$ Length of structure $\times$ freq $=$ Velocity of sound in the medium}

Data of some medicines are reproduced in Table 1 [92] and Table 2 [93]. For these studies $4.2 \mathrm{ml}$ of distilled water with 3.38 $\%$ (volume wise) of medicine was placed as the dielectric material of a capacitor type cell. Resonance frequencies relate to resonance frequencies of these cells in variable frequency electric field.

Table 1: Resonance freq of Arnica Mont.

\begin{tabular}{|c|c|c|c|}
\hline \multirow{2}{*}{ Material } & \multicolumn{3}{|c|}{ Resonance Freq in Mhz } \\
\cline { 2 - 4 } & $\mathbf{1}^{\text {st }}$ Day & $\mathbf{2}^{\text {nd }}$ Day & $\mathbf{3}^{\text {rd }}$ Day \\
\hline Control: H2O + glob & 25.6643 & 25.8336 & 25.6643 \\
\hline H2O & \multicolumn{3}{|c|}{25.495 Before adding Arn 30c } \\
\hline H2O +Arn 30c & 25.1564 & 24.8178 & 24.8178 \\
\hline H2O & \multicolumn{3}{|c|}{25.495 Before adding Arn 200c } \\
\hline H20 + Arn 200c & 24.9871 & 24.6485 & 24.6485 \\
\hline H20 & \multicolumn{3}{|c|}{26.0029 Before adding Anc 30c } \\
\hline H20 +Anc 30c & 25.41035 & 25.1564 & 25.1564 \\
\hline H20 & \multicolumn{3}{|c|}{25.6643 Before adding Anc 200c } \\
\hline H20 + Anc 200c & 25.1564 & 24.9871 & 24.9871 \\
\hline
\end{tabular}


Table 2: Resonance freq of CuMet and Graphites.

\begin{tabular}{|c|c|c|c|c|}
\hline \multirow{2}{*}{ Material } & \multicolumn{5}{|c|}{ Resonance Freq in Mhz } \\
\cline { 2 - 5 } & $\mathbf{1}^{\text {st }}$ Day & $\mathbf{2}^{\text {nd }}$ Day & $\mathbf{3}^{\text {rd }}$ Day & $\mathbf{4}^{\text {th }}$ Day \\
\hline Control H20 & 26.0029 & 26.0029 & 26.0029 & 26.3415 \\
\hline H20 & \multicolumn{5}{|c}{25.6643 Before adding CuMet-6c } \\
\hline H2O + CuMet-6c & 25.1564 & 23.802 & 23.6327 & 23.6327 \\
\hline H2O & \multicolumn{5}{|c|}{25.6643 Before adding CuMet-30c } \\
\hline H2O+CuMet-30c & 25.6643 & 24.4792 & 24.4792 & 24.4792 \\
\hline H20 & 25.495 Before adding Graphites-6c \\
\hline H20 + Graphites-6c & 23.9713 & 23.54805 & 23.71735 & 23.71735 \\
\hline H20 & 25.495 Before adding Graphites-30c \\
\hline H20+Graphites-30c & 24.4792 & 24.3099 & 24.1406 & 24.1406 \\
\hline
\end{tabular}

Other publications [94-99] of this group also advocate the structural concept. However, it must be admitted that the exact mechanism of these structural transformations are not yet established. GS Anagnostatos \& G Vithoulkas et al. [100] conjectured a possible mechanism for this phenomenon. It is called as 'clathrate model'. Till now its experimental support is lacking. But, that does not invalidate the structural concept.

\section{Homeo-Mystery - Water Structures Serve as Medicines?}

High potency homeo-medicines are merely nano-associates, that is, structured molecular groups of water carrying information about the starting medicinal substance plus its potency. And in spite of absence of any identifying chemicals they are curative agents - that is the clinical experience for over two centuries. The obvious suggestion is that water structures can serve as medicines. But general obsession of people with chemistry is so great that they refuse to accept it - how can a structure devoid of identifying chemical serve as medicine? So, our narration won't be complete without showing that water structures are capable of influencing biological systems as medicines.

We know that structural fitting and template principle explain biological metabolic processes [101]. While keeping intact the principle of conventional chemistry, the template principle introduces something extraordinary which is not found anywhere else in nature: the possibility of maintaining a strict order in the successive stages of the exceedingly long chain of reactions. So, it is natural to expect that structural matching can have a role in curative processes as well. It has been found that the membranes of most cells in living organism and giant living molecules have water on their surface in a strictly defined order to form an icelike crystal lattice. The larger the molecule the thicker is the ice envelope. The organism 'freezes' a considerable part of water it contains [1]. Sergeev further writes: "The molecules in a living organism can, for various reasons, change their form to some extent. Obviously, if the process develops considerably, such a molecule can no longer form a crust of 'ice' on its surface. The damaged molecules can be repaired with the help of tiny icicles. By 'freezing onto' curved molecules the icicles straighten them out, giving them their usual configuration". L Vlasov \& D Trifonov [102] too mention beneficial effects of melted ice (containing icecrystals) on young chickens. Hence, it is also natural to expect that the curative action of homoeopathic medicines may follow this rule. The expectation gathers strength from another striking property of water: It accommodates structurally fitting even large molecules within the hollows of ice structures, but crushes and expels those which do not fit there [1]. Straightening up is a process in between these two extremes. Over and above, health and disease of a living body is reflected in structure of cell water $[3,5]$. Reading together, administration of suitable water structure may have the power to straighten up the structure of a diseased bio-molecule and INITIATE restoration of health. This is the broad picture. Now, let us see how it conforms to experimental results.

Here also using Dielectric Dispersion Technique we obtained information about dimensions of water structures of blood serum of different persons suffering from rheumatoid arthritis and osteo-arthritis and of water structures of various homoeopathic medicines by which they were treated. The study was reported in $[103,104]$. The results are as shown in Tables $3 \& 4$ compiled from these two references.

In all these cases improvement is associated with close matching of resonance frequencies related to medicine and biosample. In these studies six medicine-soaked sugar globules (no. 10 in size) were dissolved in $5 \mathrm{ml}$ of distilled water, which was placed as the dielectric material of a capacitor type cell. Resonance frequencies in column 3 refer to resonance frequencies of these cells. Resonance frequencies in column 4 refer to resonance frequencies of similar cells for which bio-samples replaced medicines. Now, following equation (1) matching of resonance frequencies implies matching of their dimensions. This suggests that matched water structures are capable of influencing biological systems as medicines. Chemical ingredient is not mandatory for a substance to be a medicine. The results suggest that for medicinal value also Avogadro number loses its relevance in 'diluted' homeopathic medicines.

\section{Mechanism of Action}

High potency homeo-medicines lack distinctive chemical identity. They are just nano-associates of water. This makes investigation about their mechanism of action a pretty difficult job. Pinpointing the mechanism(s) and pathway(s) of action of the drug after it is administered on the tongue of a patient or an experimental animal is simply impracticable. Matsumoto [105] suggests that interaction between cell-surface proteins and clathrate-like hydrate micro-crystals formed during homeopathic dilution process to be the primary molecular mechanism of biological responses to homeopathic medicines. AR Khudabukhsh [106] suggested regulation of gene expression to be one of the major mechanisms by which homeo-drugs work. He gives an overview of the mechanism [107] where he advocated that one of the main mechanisms and pathways through which the potentised homeopathic drugs act could be by regulation of expression of some specific and relevant genes. In another review article [108] he comes forward with evidences in support of his hypothesis according to which homeopathic remedies carry specific "signals" that can be identified by specific receptors and can act as a trigger to turn "on" or "off" some relevant genes, initiating a cascade of down-stream gene actions to alter and correct the gene expressions that had gone wrong to produce the disorder/disease condition. Evidence of gene regulatory hypothesis is also available from other publications of his group [109-112]. 
Now, consider the parallelism of this concept with action of antibiotics, which act on the principle of structural locking/ binding [113]. Just replace "signal" (of Khudabukhsh) by 'matching structure' which can structurally lock/bind to the specific receptor/target. In case of mainstream medicine the structure is of the chemistry of the antibiotic, whereas in case of homeopathy it is the structure of nano-associates of water. It is interesting to note that out of six different mechanisms of action of drugs mentioned in this reference physically acting drugs like bisacodyl or charcoal do not produce any effect on the physiology and act superficially. Similarly the second category of drugs acting by chemical reaction (like sodium bicarbonate or lime) does not touch the actual cause of malfunction of the system. Morphine related drugs, diuretics and pain relieving drugs falling in the third category of drugs modify physiological function but do not revert it to healthy state. The drugs of fourth category used in depression, schizophrenia, anxiety and drugs of abuse function through receptors. Homeopathic drugs as pointed out by Khudabukhsh also function through receptors. But there is qualitative difference. Drugs by replacement like levodopa used in Parkinson's disorder falling in the fifth category subsides the symptoms temporarily. Drugs by substitution fall in the sixth category. It is the mechanism of action of antibiotics. The gene regulatory mechanism is parallel to this as stated above. It is very effective treatment against bacteria, virus and possibly cancer also in both homeopathy and non-homeopathy.

Note that structural matching is evidenced by the data in Table 3 and Table 4 above. The structural concept has been advocated by CR Mahata [114-117]. Here the argument is from a generalized perspective, a change of focus - avoiding hard medical terminology. The thrust of the argument is: action of homeo-drugs of high potency cannot be explained by chemical reaction. We must change the focus from chemical formula to physical structure. Chemical affinity is to be viewed as structural affinity, that is, ability to fit structurally. The bio-molecule which can structurally fit with the medicine-structure automatically becomes the target or receptor. Further, he argues that any chemical reaction may also be viewed as interaction between structures, because every chemical substance has its own defining structure. So, all kinds of medicinal action can be considered to be structural interaction be it homeopathy or non-homeopathy. And this is a generalized concept. Accordingly, medicine is re-defined as below.

A substance is to be recognized as a medicine if it has the capability of curing disease(s) while its medicinal property is to be attributed to molecular structure of vehicle like water or of distinct chemical substance when it exists.

Table 3: Comparison of resonance freq of medicine vs bio-sample of patients.

\begin{tabular}{|c|c|c|c|c|}
\hline Sl. No. & Medicine Administered & $\begin{array}{c}\text { Medicine- Related } \\
\text { Resonance Freq }\end{array}$ & $\begin{array}{c}\text { Bio-Sample -Related } \\
\text { Resonance Freq }\end{array}$ & Result \\
\hline 1 & Guaiacum 30c & $22.9 \mathrm{MHz}$ & $22.5 \mathrm{MHz}$ & Marked improvement \\
\hline 2 & Sulphur 200c & $23.5 \mathrm{MHz}$ & $23.2 \mathrm{MHz}$ & Moderate improvement \\
\hline 3 & Natrum Mur 30c & $23.8 \mathrm{MHz}$ & $24.9 \mathrm{MHz}$ & No improvement \\
\hline
\end{tabular}

Table 4: Comparison of resonance freq of medicine vs bio-sample of patients.

\begin{tabular}{|c|c|c|c|c|}
\hline Sl. No. & Medicine Administered & $\begin{array}{c}\text { Medicine- Related } \\
\text { Resonance Freq }\end{array}$ & $\begin{array}{c}\text { Bio-Sample- Related } \\
\text { Resonance Freq }\end{array}$ & Result \\
\hline 1 & Rhus Tox 200c & $22.8 \mathrm{MHz}$ & $22.8 \mathrm{MHz}$ & Marked improvement \\
\hline 2 & Rhus Tox 200c & $22.8 \mathrm{MHz}$ & $23.6 \mathrm{MHz}$ & Less improvement \\
\hline 3 & Thuja 30c & $23.6 \mathrm{MHz}$ & $23.6 \mathrm{MHz}$ & Moderate improvement \\
\hline 4 & Thuja 30c & $23.6 \mathrm{MHz}$ & $24.2 \mathrm{MHz}$ & No improvement \\
\hline 5 & Thuja 30c & $23.6 \mathrm{MHz}$ & $23.4 \mathrm{MHz}$ & Moderate improvement \\
\hline 6 & Medorrhinum 200c & $28.6 \mathrm{MHz}$ & $22.8 \mathrm{MHz}$ & No improvement \\
\hline
\end{tabular}

\section{Conclusion}

The logical analysis of data and information obtained so far leads only to one possibility and that is structural concept of medicine. It explains actions of homeopathy as well as nonhomeopathy. It also resolves more than two-century old conflict between homeopathy and non-homeopathy. I am convinced that people will be immensely benefitted by wider use of homeopathy - the most economic system of medicine, as they will get a safe (without side effects), subtle (chemical-free) and quite often a superior health care system (giving near-miraculous cures) so long they are in the domain of medicinal care. I hope that this work will go a long way in achieving this goal.

\section{Acknowledgement}

The infrastructural facility provided by IIEST, Shibpur, funding by UGC and AYUSH of Govt. of India and free supply of medicines etc by HAPCO, Kolkata at different stages of this research are gratefully acknowledged.

\section{Conflict of Interest}

None.

\section{References}

1. Sergeev B (1971) Physiology for Everyone. Mir Pub, Moscow, Russia, p. 11-16. 
2. Finkelnburg W (1964) Structure of Matter. Academic Press, New York, USA, pp. 412-414

3. Chaughule RS (1978) NMR: A new eye on cancer. Science Today, p. 23-27.

4. Damadian R (1971) Tumour detection by Nuclear Magnetic Resonance. Science 171(3976): 1151-1153.

5. Ranade SS, Shah S, Korgaonkar KS, Kasturi SR, Chaughule RS, et al. (1976) Absence of correlation between spin-lattice relaxation times and water content in human tumour tissues. Physiol Chem Physics 8(2): 131-134.

6. Mahata CR (1997) Homoeopathy explained in the light of recognised science. The homoeopathic heritage 22(2): 245-252.

7. Giudice ED, Preparata G, Vitiello G (1988) Water as a free electric dipole laser. Phys Rev Lett 61(9): 1085-1088.

8. Arani R, Bono I, Giudice ED, Preparata G (1995) QED Coherence and the Thermodynamics of water. Int J Modern Phys 9(5): 1813-1841.

9. Lo SY, Geng X, Gann D (2009) Evidence for the existence of stable water-clusters at room temperature and normal pressure. Phys Lett A 373(42): 3872-3876.

10. Ho MW (2014) Large Supramolecular Water Clusters Caught on Camera - A Review. Water 6: 1-12.

11. Marchettini N, Giudice E Del, Voeikov V, Tiezzi E (2010) Water: A medium where dissipative structures are produced by a coherent dynamics. J Theor Biol 265(4): 511-516.

12. Yinnon C, Yinnon TT (2009) Domains in aqueous solutions: Theory and experimental evidence. Modern Physics Letters B 23(16): 1959 1973.

13. Germano R (2015) Water's quantum structures and life. Electromagn Biol Med 34(2): 133-137.

14. Bano I, Giudice ED, Gamberale L, and Henry M (2012) Emergence of the Coherent Structure of Liquid Water. Water 4: 510-532.

15. http://www.i-sis.org.uk/water4.php

16. Zheng JM, Chin WC, Khijniak E, Khijniak E, Pollack GH (2006) Surfaces and interfacial water: evidence that hydrophilic surfaces have longrange impact. Adv Colloid Interface Sci 127(1): 19-27.

17. Giudice ED, Tedeschi A, Vitiello G, Voeikov V (2013) Coherent structures in liquid water close to hydrophilic surfaces. J Phys Conf Ser 442(1): 012028.

18. Elia V, Germano R, Napoli E (2015) Permanent Dissipative Structures in Water: The Matrix of Life? Experimental Evidences and their Quantum Origin. Curr Top Med Chem 15(6): 559-571.

19. Elia, V, Napoli E, Niccoli M (2013) Calorimetric and Conductometric titrations of nanostructures of water molecules in Iteratively Filtered Water. JTAC 111(1): 815-821.

20. Elia V, Ausanio G, De Ninno A, Germano R, Napoli E, et al. (2014) Experimental Evidences of Stable Water Nanostructures At Standard Pressure And Temperature Obtained by Iterative Filtration. Water 5: 121-130.

21. Capolupo A, Giudice ED, Elia V, Germano R, Napoli E, et al. (2013) Selfsimilarity properties of nafionized and filtered water and deformed coherent states. Int J Mod Phys B 28: 3.
22. Elia V, Marchettini N, Napoli E (2013) Calorimetric, Conductometric and Density Measurement of Iteratively Filtered Water using Millipores Filters of 450, 200, 100 and 25nm. J Therm Anal Calorimetry 114(2): 927-936.

23. Elia V, Napoli E (2012) Nanostructures of Water Molecules in Iteratively Filtered Water. Key Engineering Materials 495: 37-40.

24. Cattaneo TMP, Vero S, Napoli E, Elia V (2011) Influence of Filtration Process on Aqueous Nanostructures by NIR Spectroscopy. J Chem Eng 5: 1046-1052.

25. Elia, V, Ausanio G, De Ninno A, Gentile F, Germano R, et al. (2013) Experimental evidence of stable aggregates of water at room temperature and normal pressure after iterative contact with Nafion polymer membrane. Water 5: 16-26.

26. Capolupo A, Del Giudice E, Elia V, Napoli E, Niccoli M, et al. (2014) Self-similarity properties of nafionized and filtered water and deformed coherent states. Int J Mod Phys B 28: 3.

27. Elia V, Lista L, Napoli E, Niccoli M (2014) A Thermodynamic Characterization of Aqueous Nanostructures of Water Molecules Formed by Prolonged Contact Hydrophilic Polymer Nafion. J Therm Anal Calorimetry 115(2): 1841-1849.

28. Elia V, Napoli E, Niccoli M (2013) Physical-chemical Study of Water in Contact with a hydrophilic polymer: Nafion J Therm Anal Calorimetry 112 (2): 937-944.

29. Elia V, Napoli E, Niccoli M (2009) A molecular model of interaction between extremely diluted solutions and $\mathrm{NaOH}$ solutions used as titrant: Conductometric and pHmetric titrations. J Mol Liq 148(1): $45-50$.

30. Elia V, Napoli E, Germano R (2007) The 'Memory of water': an almost deciphered enigma. Dissipative structures in the extremely diluted aqueous solutions. Homeopathy 96(3): 163-169.

31. Elia V, Napoli E (2010) Dissipative Structures in Extremely Diluted Solutions of Homeopathic Medicines. A Molecular Model based on Physico-Chemical and Gravimetric evidences. Int J Des Nat 5: 39-48.

32. Elia V, Ausanio G, Gentile F, Germano R, Napoli E, et al. (2014) Experimental evidence of Stable Water Nanostructures in Extremely Diluted Solutions, at Standard Pressure and Temperature. Homeopathy 103(1): 44-50.

33. Yinnon TA, Elia V (2013) Dynamics in perturbed very Dilute Aqueous Solutions: Theory and Experimental Evidence. Int J Modern Phys B 27: 5 .

34. Elia V, Niccoli M (1999) Thermodynamics of extremely diluted aqueous solutions. Ann NY Acad Sci 879: 241.

35. Elia V, Niccoli M (2004) New Physico-chemical properties of extremely diluted aqueous solutions. J. Therm. Anal. Calorimetry, 75, 815-836.

36. Elia V, Baiano S, Duro I, Napoli E, Niccoli M, et al. (2004) New and permanent physicochemical properties of the extremely diluted aqueous solutions of the homeopathic medicine. A conductivity measurements study at $251 \mathrm{C}$ in function of the age of the potencies. Homeopathy 93(3): 144-150.

37. Elia V, Napoli E, Niccoli M, Montanino M, Napoli E, et al. (2004) New physico-chemical properties of extremely dilutedaqueous solutions. A calorimetric and conductivity study at $25{ }^{\circ} \mathrm{C}$. J Therm Anal Calorimetry 78: 331-342. 
38. Elia V, Marchese M, Montanino M, Napoli E, Niccoli M, et al. (2005) A Hydrohysteretic phenomena of 'extremely diluted solutions' induced by mechanical treatments. A calorimetric and conductometric study at $25^{\circ} \mathrm{C}$. J Solution Chem 34(8): 947-960.

39. Elia V, Elia L, Cacace P, Napoli E, Niccoli M, et al (2006) Extremely diluted solutions asmulti-variable systems. A study of calorimetric and conductometric behaviour as function of the parameter time. Therm Anal Calorimetry 84(2): 317-323.

40. Elia V, Elia L, Marchese M, Montanino M, Napoli E, et al (2007) Interaction of 'extremely diluted solutions' with aqueous solutions of hydrochloric acid and sodium hydroxide. A calorimetric study at 298 K. J Mo l Liq 130(1-3): 15-20.

41. Elia V, Elia L, Montanino M, Napoli E, Niccoli M, et al. (2007) Conductometric studies of the serially diluted and agitated solutions. On an anomalous effect that depends on the dilution process. J Mol Liq 135(1-3): 158-165.

42. Elia V, Elia L, Napoli E, Montanino M, Niccoli M, et al. (2006) Conductometric and calorimetric studies of serially diluted and agitated solutions: the dependence of intensive parameters on volume. Int J Ecodyn 1(4): 1-12.

43. Elia V, Marchettini N, Napoli E Niccoli M (2014) The role of Ethanol in Extremely Diluted Solutions. Calorimetric and Conductometric measurements. J Therm Anal Calorimetry 116(1): 477-483.

44. Yinnon TA, Elia V (2013) Dynamics in perturbed very Dilute Aqueous Solutions: Theory and Experimental Evidence. Int J Modern Phys B $27(5)$

45. Elia V, Napoli E, Niccoli M (2013) On the stability of Extremely Diluted Solutions to Temperature. J Therm Anal Calorimetry 113(2): 963-970.

46. Betti L, Elia V, Napoli E, et al (2011) Biological effects and physicochemical properties of extremely diluted aqueous solutions as a function of aging-time. Frontiers Life Sci 5(3-4): 117-126.

47. Elia V, Marrari L, Napoli E (2012) Aqueous Nanostructures in water induced by Electromagnetic Field Emitted by EDS. A Conductometric Study of Fullerene and Carbon Nanotube EDS. J Therm Anal Calorimetry 107(2): 843-851.

48. Elia V, Napoli E (2010) Dissipative Structures in Extremely Diluted Solutions of Homeopathic Medicines. A Molecular Model based on Physico-Chemical and Gravimetric evidences. IJDN 5(1): 39-48.

49. Elia V, Napoli E, Niccoli M (2009) A Molecular Model of Interaction between Extremely Diluted Solutions and $\mathrm{NaOH}$ Solutions Used as Titrant. Conductometric and pHmetric Titrations. JML 148(1): 4550.

50. Cacace CM, Elia L, Elia V, Napoli E, Niccoli M, et al. (2009) Conductometric and pHmetric Titrations of Extremely Diluted Solutions Using $\mathrm{HCl}$ Solutions as Titrant. A Molecular Model. JML 146(3): 122-126

51. Ciavatta L, Elia V, Napoli E, Niccoli M (2008) New Physico-Chemical Properties of Extremely Diluted Solutions. Electromotive Force Measurement of Galvanic Cells Sensible to the Activity of $\mathrm{NaCl}$ at 25 ${ }^{\circ} \mathrm{C}$. JSC 37(8): 1037-1049

52. Elia V, Elia L, Marchettini N, Napoli E, Niccoli M, et al. (2008) PhysicoChemical Properties of aqueous Extremely Diluted Solutions in Relation to Ageing. JTAC 93(3): 1003-1011.

53. Elia V, Napoli E, Niccoli M (2008) On the stability of Extremely Diluted Aqueous Solutions at the High Ionic Strength. A Calorimetric Study at 298K. JTAC, 92(2): 643-648.
54. Belon P, Elia V, Elia L, Napoli E, Niccoli M, et al. (2008) Conductometric and Calorimetric studies of the Diluted and Agitated Solutions. On the combined Anomalous Effect of Time and Volume parameters. J Therm Anal Calorimetry 93(2): 459-469.

55. Elia V, Napoli E, Niccoli M, Marchettini N, Tiezzi E, et al. (2008) New Physico-Chemical Properties of Extremely Dilute Solutions. A Conductivity Study at $25{ }^{\circ} \mathrm{C}$ in Relation to Ageing. J Solution Chem 37(1): 85-96.

56. Konovalov AI and Ryzhkina IS (2014) Formation of nano-associates as a key to understanding of physicochemical and biological properties of highly dilute aqueous solutions. Russian Chemical Bulletin, International Edition 63(1): 1-14.

57. Konovalov AI, Ryzhkina IS, Murtazina LI (2008) Supramolecular systems based on the melamine salt of bis (hydroxymethyl) phosphinic acid (melafen) dihydrate and surfactants - 1. Structure and self-association of melafen in water and chloroform. Russ Chem Bull 57(6): 1231-1238.

58. Ryzhkina IS, Murtazina LI, Kiseleva YuV, Konovalov AI (2009) Properties of supramolecular nanoassociates formed in aqueous solutions of biologically active compounds in low or ultra-low concentrations. Dokl Phys Chem 428: 196.

59. Ryzhkina IS, Murtazina LI, Kiseleva YuV, Konovalov AI (2009) Supramolecular systems based on amphiphilic derivatives of biologically active phenols: Self-assembly and reactivity over a broad concentration range. Dokl Phys Chem 428: 201.

60. Ryzhkina IS, Kiseleva YuV, Zheltukhina GA, Okorochenkov SA Murtazina LI, et al. (2011) Relationship between self-organization, physicochemical properties, and biological activity of aqueous solutions of hemin derivatives. Dokl Phys Chem 440: 157.

61. Ryzhkina IS, Murtazina LI, Nemtare AV, Mironov VF, Katayev EA, et al. (2011 Aug) Self-association of a phosphate receptor along and with a lipidomimetic in water: Effect of receptor low concentrations on the catalytic activity of mixed systems. Chem Phy Lett 5(511): 247-250.

62. Ryzhkina IS, Murtazina LI, Nemtarev AV, Vladimir F Mironov, Alexander I, et al. (2010) Supramolecular water systems based on the new amphiphilic phosphacoumarins: synthesis, self-organizations and reactivity. Mendeleev Commun 20(3): 148-150.

63. Ryzhkina IS, Kiseleva YuV, Murtazina LI, Mishina OA, Sherman ED, et al. (2012) Comparative study of self-organization and physicochemical properties of highly diluted aqueous solutions of phenol bioantioxidants. Dokl Phys Chem 447(1): 203-206.

64. Pal'mina NP, Chasovskaya TE, Ryzhkina IS, Murtasina LI, Konovalov AI, et al. (2009) Water solutions of phenosan potassium salt Influence on biological membrane structure and conductivity. Dokl Biochem Biophys 429: art 301.

65. Ryzhkina IS, Murtazina LI, Masagutova EM, et al. (2012) Selforganization of sodium chloride solutions in the absence and presence of a biologically active substance of low concentration under common and hypoelectromagnetic conditions. Dokl Phys Chem 446: 184-189.

66. Ryzhkina IS, Kiseleva YuV, Murtazina LI, Valitov N, Solov'eva ES, et al (2010) Nanosized mixed aggregates of alkylated p-sulfonatocalix[n] arenes and cetyltrimethylammonium bromide: self-organization and catalytic activity. Russ Chem Bull 59(7): 1327-1335.

67. Ryzhkina IS, Kiseleva YuV, Mishina OA, Timoshevaa AP, Yu S, et al (2013) Correlations between the self-organization, physicochemica properties and biological activity of Mebicar in dilute aqueous solutions Mendeleev Commun 23(5): 262-264. 
68. Ryzhkina IS, Kiseleva YuV, Mishina OA, Murtazina LI, Sudakova SN, et al. (2013) Influence of spatial isomerism of tetrathiacalix[4] arene functionalized by hydrazide groups on self-organization and physicochemical properties of aqueous dimethyl sulfoxide solutions of low concentration. Dokl Phys Chem 453(1): 264-269.

69. Ryzhkina IS, Murtazina LI, Kiseleva YuV, Konovalov AI (2009) Supramolecular Systems Based on Amphiphilic Derivatives of Biologically Active Phenols: Self_Assembly and Reactivity over a Broad Concentration Range. Doklady Physical Chemistry 428: 201205

70. Ryzhkina IS,. Kiseleva YuV, Murtazina LI, Pal'mina NP, Belov VV, et al. (2011) Effect of $\alpha_{-}$Tocopherol Concentrations on the Self Organization, Physicochemical Properties of Solutions, and the Structure of Biological Membranes. Doklady Physical Chemistry 438(2): 109-113.

71. Ryzhkina IS, Murtazina LI, Kiseleva YuV, Konovalov AI (2015) Self_ Organization and Physicochemical Properties of Aqueous Solutions of the Antibodies to Interferon Gamma at Ultrahigh Dilution. Doklady Physical Chemistry 462(1): 110-114.

72. Lunev IV, Khamzin AA, Popov II (2014) Dielectric Spectroscopy Study of low Concentration Aqueous Solutions of a Calix[4]resorcinarene Derivative. Doklady Akademii Nauk 455(6): 656-660.

73. Konovalov AI, Ryzhkina IS, Murtazina LI, Kiseleva YuV (2014) Forming the nanosized molecular assemblies (nanoassociates) is a key to understand the properties of highly diluted aqueous solutions. Biofizika 59(3): 421-427.

74. Konovalov AI, Mal'tseva EL, Ryzhkina IS, Murtazina LI, Kiseleva V, et al. (2014) Formation of Nanoassociates Is a Factor Determining Physicochemical and Biological Properties of Highly Diluted Aqueous Solutions. Doklady Akademii Nauk 456(2): 86-89.

75. Konovalov AI (2013) The formation of nanosized molecular ensembles in highly dilute aqueous solutions. Vestnik Rossiiskoi Akademii Nauk 83(6): 513-519.

76. Konovalov AI, Ryzhkina IS (2014) Highly diluted aqueous solutions: Formation of nano-sized molecular assemblies (nanoassociates) Geochemistry International 52(13): 1207-1226.

77. Ryzhkina IS, Kiseleva YuV, Mishina OA, Masagutova EM, Sergeeva SY, et al. (2014) Highly diluted solutions of amphiphilic derivatives of calix[4]resorcinols: Self-organization and physicochemical properties. Russian Chemical Bulletin 63(6): 1399-1408.

78. Ryzhkina IS, Murtazina LI, Konovalov AI (2011) Action of the external electromagnetic field is the condition of nanoassociate formation in highly diluted aqueous solutions. Dokl Phys Chem 440(): 201-204.

79. Ryzhkina IS, Kiseleva YuV, Murtazina LI, Konovalov AI (2012) Effect of ultralow concentrations and electromagnetic fields. Dokl Phys Chem 446(1): 153-157.

80. Ryzhkina IS, Kiseleva YuV, Timosheva AP, Safiullin RA, Kadirov MK, et al. (2012) Low-concentration aqueous solutions of an amphiphilic calix[4]resorcinarene derivative: Self-organization, physicochemical properties, and biological activity under common and hypoelectromagnetic conditions. Dokl Phys Chem 447(1): 193199

81. Konovalov DA, Murtazina LI, Ryzhkina IS, Konovalov AI (2015) Effect of Weak Electromagnetic Fields on Self_Organization of Highly Diluted Solutions of Alkylated p_Sulfonatocalix [6]arene. Doklady Akademii Nauk 463(2): 179-182.
82. Konovalov A, Ryzhkina I, Maltzeva E, Murtazina L, Kiseleva Y, et al. (2015) Nanoassociate formation in highly diluted water solutions of potassium phenosan with and without permalloy shielding. Electromagn Biol Med 34(2): 141-146.

83. Montagnier L, Giudice ED, Jamal A"issa, Lavallee C, Motschwiller S, et al. (2014 Dec) Transduction of DNA information through water and electromagnetic waves. Electromagnetic Biology and Medicine34: 1-11.

84. Yinnon TA, Liu ZQ (2015) Domains Formation Mediated by Electromagnetic Fields in Very Dilute Aqueous Solutions: 1. Quantum Electrodynamic Aspects. WATER 7: 33-47.

85. Yinnon TA, Liu ZQ (2015) Domains Formation Mediated by Electromagnetic Fields in Very Dilute Aqueous Solutions: 2. Quantum Electrodynamic Analyses of Experimental Data on Strong Electrolyte Solutions. WATER 7: 48-69.

86. Yinnon TA, Liu ZQ (2015) Domains Formation Mediated by Electromagnetic Fields in Very Dilute Aqueous Solutions: 3. Quantum Electrodynamic Analyses of Experimental Data on Solutions of Weak Electrolytes and Non-electrolytes. WATER 7: 70-95.

87. Yinnon TA, Yinnon CA (2012) Domains of solvated ions in aqueous solutions, their Characteristics and impact on electric conductivity: Theory and experimental evidence. Modern Physics Letters B 26(2): 14.

88. Yinnon TA, Yinnon CA (2011) Electric dipole aggregates in very dilute polar liquids: Theory and experimental evidence. International Journal of Modern Physics B 25(28): 3707-3743.

89. Maity Tanmoy, Ghosh D, Mahata CR (2007) Theory and Instrumentation related to Potentised Homoeopathic Medicines. IE(I) Journal 2(3): 27-31.

90. Maity Tanmoy, Ghosh D, Mahata CR (2007) Theory and Instrumentation related to anomalous dielectric dispersion in ordered molecular groups. Sensors and Transducers 85(11): 17451756.

91. Maity T, Ghosh D and Mahata CR (2010) Effect of Dielectric Dispersion on Potentised Homoeo-Medicines. Homeopathy 99(2): 99-103.

92. Mahata CR (2013) Dielectric Dispersion Studies Indicate Change in Structure of Water by Potentised Homeopathic Medicines. IE(I) 93(4): 231-235.

93. Mahata CR (2013) Dielectric Dispersion Studies of Some Potentised Homoeopathic Medicines Reveal Structured Vehicle. Homeopathy 102(4): 262-267.

94. Sadhukhan M, Sutradhar A, Syam P, Mahata CR and Chattopadhyay R (2010) Mystery of potentised substances: some significant attempts to unveil it. IEEE Xplore.

95. Maity T, Ghosh D, Mahata CR (2010) In Search Of A Technique For Identifying Potentised Homoeo-Medicines Beyond Avogadro Limit Indian Journal of Research in Homoeopathy 4(3): 1-9.

96. Chattopadhyay R, Sadhukhan M, Pal A, Sutradhar A, Syam P, et al (2012) On electromagnetic signals from vastly diluted DNA solutions, potentised medicines and inorganic metals. Wesleyan Journal of Research 5(1): 50-55.

97. Chattopadhyay R, Mahata CR (2016) Molecular Level Correlation between Probable Homoeopathic Medicines and Bio-Samples of Patients. Int J Complement Alt Med 3(4): 1-4. 
98. Chattopadhyay R, Mahata CR (2016) A Fundamental Study to Observe Correlation at Molecular Level between Bio-Samples of Patients and Indicated Homoeopathic Medicines. Int J High Dilution Res 15(3): 11-17

99. Mahata CR (2016) Quantum Electro-Dynamics helps Homoeopathy achieve its Scientific Basis. MOJ Proteomics \& Bioinformatics 3(6): $1-3$.

100.Anagnostatos GS, Vithoulkas G, Garzonis P, Tavouxoglou C (1991) A working hypothesis for homoeopathic microdiluted remedies. Berlin J Resear Homoeopathy 1(3): 141-147.

101.Kamshilov M, M (1974) Evolution of Biosphere. Mir Pub, Moscow, Russia, p. 110-113.

102.Vlasov L and Trifonov D (1977) 107 Stories about Chemistry. Mir Pub, Moscow, Russia, p. 70-72.

103.Chattopadhyay V, Mahata CR (2016) Molecular Level Correlation between Probable Homoeopathic Medicines and Bio-Samples of Patients. IJCAM 3(4): 1-4.

104.R Chattopadhyay \& C R Mahata (2016) A Fundamental Study to Observe Correlation at Molecular Level between Bio-Samples of Patients and Indicated Homoeopathic Medicines. IJHDR 15(3): 1117.

105.Matsumoto J (1995) Molecular mechanism of biological responses to homeopathic medicines. Med Hypoth 45(3): 292-296.

106.Khuda-Bukhsh AR (1997) Potentized homeopathic drugs act through regulation of gene expression: A hypothesis to explain their mechanism and pathways of action in vivo. Comp Ther Med 5(1): 4346.

107.Khuda-Bukhsh AR (2003) Towards understanding molecular mechanisms of action of homeopathic drugs: An overview. Molecular and Cellular Biochemistry 253(1-2): 339-345.

108.Khuda-Bukhsh AR (2014) Current trends in high dilution research with particular reference to gene regulatory hypothesis. Nucleus March 57(1): 3-17.
109.Das D, De A, Dutta S, Biswas R, Boujedaini N, et al. (2011) Potentized homeopathic drug Arsenicum Album 30C positively modulates protein biomarkers and gene expressions in Saccharomyces cerevisae exposed to arsenate. Zhong Xi Yi Jie He Xue Bao 9(7): 752760.

110. Saha SK, Das S, Khuda-Bukhsh AR (2012) Phenotypic evidence of ultra-highly diluted homeopathic remedies acting at gene expression level: a novel probe on experimental phage infectivity in bacteria. Zhong Xi Yi Jie He Xue Bao 10(4): 462-470.

111. Saha SK, Sourav Roy, Khuda-Bukhsh AR (2013) Evidence in support of gene regulatory hypothesis: Gene expression profiling manifests homeopathy effect as more than placebo. Int J High Dilution Res 12(45): 162-167.

112.Khuda-Bukhsh AR, Das S, Saha SK (2014) Molecular approaches toward targeted cancer prevention with some food plants and their products: inflammatory and other signal pathways. Nutr Cancer 66(2): 194-205.

113.http://www.naturalremedieshome.com/drug-mechanism-ofaction.

114.Mahata CR (2016) Homoeopathic Challenge Addressed by Some Striking Facts and Research Findings Culminates in a Generalized Concept of Medicines. MOJ Proteomics \& Bioinformatics 3(2): 1-6.

115.Mahata CR (2015) Structural model explains high potency homoeopathic medicines and leads to a generalized understanding of medicines. Int J Complement \& Alt Med 1(2): 1-3.

116.Mahata CR (2016) A Generalized Concept of Medicine Emerging from Homoeo-Research Incorporating Quantum Electro-Dynamics. Int J Complement Alt Med 4(1): 1-6.

117.Mahata CR (2015) Revising the Concept of Medicine and Presenting a Unified One. Paper presented at ICHM at Kerala, Sep 11-13. 